\title{
Employees' self-expansion as a mediator between perceived work conditions and work engagement and productive behaviors
}

\author{
Paweł Jurek $^{1}$ (D) $\cdot$ Tomasz Besta $^{1}$ \\ Published online: 29 March 2019 \\ (C) The Author(s) 2019
}

\begin{abstract}
There has been increasing scientific interest in the relationships between self-perception and group identity development processes as well as the behavioural implications of these processes in organizational contexts. Recently, the concept of workplace self-expansion has been introduced to work and organizational psychology. That is, the self-expanding characteristics of work and the workplace have been related to job satisfaction and organizational commitment. In the following studies, we examined the importance of workplace self-expansion and found that it is a significant mediator between job resources (e.g. compensation and benefits, job tasks) and work engagement (Study 1) as well as task-oriented engagement (Study 2). At the same time, our findings prove that job demands (e.g. role ambiguity, overload) do not weaken employees' self-expansion if the impact of job resources is taken into account.
\end{abstract}

Keywords Workplace self-expansion $\cdot$ Job resources $\cdot$ Job demands $\cdot$ Work engagement $\cdot$ Productive behaviours

\section{Introduction}

The importance of self-concept in the workplace has been at the centre of much research (Judge and Bono 2001). For example, previous analyses revealed that neuroticism, self-esteem, and locus of control are linked to the two central factors in human resource management: job satisfaction and job performance (Bono and Judge 2003). Moreover, there is a growing interest in studies which focus on identity-based variables and their relation to organizational commitment and job satisfaction. In this vein, a cross-sectional survey of university faculty by van Knippenberg and Sleebos showed that identification with an organization is associated with the self-referential aspect of organizational membership and reflects a feeling of identity, whereas commitment is related to perceived organizational support and job satisfaction (van Knippenberg and Sleebos 2006). Other authors also agree that identity and organizational identification on the one hand, and commitment on the other, are distinguishable in terms of their meaning for employees and behavioural implications (Meyer et al. 2006). That is, a salient social

Paweł Jurek

psypj@ug.edu.pl

Institute of Psychology, University of Gdansk, Gdansk, Poland identity involves perceiving oneself as being part of a larger whole, i.e. a company or nation. Meyer et al. pointed out that because people can belong to multiple groups (such as organizations, work teams, or subgroups of employees), multiple social identities can be formed. Importantly, at any given time, one or more of these social identities might be dominant and shape one's behaviour (Meyer et al. 2006). Thus, the behavioural consequences of identification seem to be less relevant to overall group functioning (e.g. job performance) than those of commitment. Commitment can bind an individual to a social (or non-social) target and to an action tendency linked to that target. In this view, commitment is more conscious than identity, and its consequences are more relevant to behaviours in an organization.

In this article, we would like to introduce the selfexpansion process, which is related to self-growth and identity development, and show how it could be related to organizational behaviors and work engagement. We explore the importance of the self-expanding characteristics of work and the workplace (e.g. the ability to develop new perspectives, capabilities, social identities, and challenging and novel activities) for work engagement and organizational productive behavior. Specifically, based on the self-expansion model (Wright et al. 2002) and previous research on workplace self-expansion (McIntyre et al. 2014), we analysed whether the experience of workplace self-expansion (a) is related to work engagement and organizational productive behavior and (b) mediates 
the relationship between job resources (i.e. compensation and benefits, job tasks) and work engagement (Study 1) and organizational productive behavior, with job demands as control variables (Study 2).

\section{Meaning of Self-Growth and Self-Development for Employees}

According to previous research, fulfilment of the need for selfgrowth is essential if an employee is to be motivated to perform challenging jobs and tasks (Lin et al. 2016). This presumption has been tested in different ways in various organizational settings. For example, Hytti et al. (2013) examined the influence of novel and challenging tasks on job satisfaction. Their study found that job satisfaction is contingent upon fulfilment of the need to be engaged in jobs that are high in autonomy, variety, and task significance (Hytti et al. 2013).

Other views on how the work environment can lead to self-growth aim at identifying job characteristics related to organization-based variables. For example, examination of the antecedents of organization-based self-esteem showed that job complexity is one of its important determinants (Lee 2003).

The psychological processes that lead to self-growth and self-enrichment were also analysed beyond mere engagement and organizational behaviors, i.e. in the context of work-life balance. A study on Australian employees from four different organizations found that work-tofamily enrichment and family-to-work enrichment were positively related to self-efficacy, which in turn had a positive effect on work-life balance (Chan et al. 2016).

The aforementioned studies illustrate a variety of psychological mechanisms related to self-growth and the consequences of these job characteristics or workplace environments that allow for self-growth and self-development. Self-expansion theory could help in integrating various perspectives on the role of self and identity in organizational settings and introduce motivators that could be mediators between job characteristics (i.e. compensation and benefits, job tasks) and work engagement and organizational behaviors. We focus here on self-expansion related to the work environment. As there are various paths to selfgrowth, self-expansion through engaging in novel and exciting work tasks is only one means of self-development. But, as it specifically targets organizational norms and behaviours, workplace self-expansion should be a particularly important characteristic that predicts work engagement.

\section{Self-Expansion Model}

The self-expansion model highlights that the process of enriching the self is related to changes in self-concept. Specifically, people who fulfil their need to expand and broaden themselves acquire new perspectives, identities, and mental resources. These, in turn, help with the challenges of daily life as well as with complex tasks in the workplace. Initially, most research on self-expansion has focused on it in the context of romantic relationships. That is, on questions regarding how incorporating a significant other/others into one's self-construct influences one's self-perception and behaviors (e.g. Aron and Aron 1996). In this vein, Aron et al. (1995) found that falling in love with a significant other increases the size of one's self-concept and self-efficacy. An increasing number of studies examine other pathways to a broadened sense of self. Based on previous research, McIntyre et al. (2014) stressed that self-expansion typically occurs as a result of (a) completing novel and challenging tasks and (b) by directly acquiring new perspectives, resources, and identities. In this view, engaging in activities that are perceived as novel, exciting, and interesting could have similar consequences to broadening the self by including others (Mattingly and Lewandowski Jr 2013).

Self-expansion could be considered a need to fulfil, and this need is especially important in motivating people when the external environment is safe and secure (Wright et al. 2002). Self-expansion is also linked to control motives. As Wright et al. (2002) noted, expanding the self by acquiring new knowledge as well as novel perspectives and identities allows one to directly influence and control one's environment. Although the need for autonomy is often considered crucial for developing a sense of agency (Little et al. 2006), a greater feeling of agency could be achieved by fulfilment of the need for self-expansion (Aron and Aron 1996; Besta et al. 2016; Mattingly and Lewandowski Jr 2014). In this context, realization of the self-expansion motive is considered an antecedent of belief in one's self-efficacy, and has been shown to be indeed associated with an increased sense of self-efficacy (Mattingly and Lewandowski Jr 2013). Self-expansion is also linked with a greater likelihood of accomplishing goals $(\mathrm{Xu}$ et al. 2010), willingness to engage in collective action (Besta et al. 2018), and increased approach motivation (Mattingly et al. 2012). Losing a self-expanding job results in lowered self-concept clarity and self-esteem (McIntyre et al. 2014). Nevertheless, only a few studies to date have directly focused on workplace self-expansion (e.g. Besta and Jurek 2016; McIntyre et al. 2014). Thus, we aimed to explore the role workplace self-expansion plays in the relationship between job resources, work engagement, and organizational productive behavior.

\section{Job Demands-Resources Theory}

In the most recent version of the job demands-resources theory, the authors propose that all working conditions can be classified in two main categories - namely, job demands and job resources-which have unique properties and 
consequences (Bakker and Demerouti 2017, 2018). Job demands are the aspects of work that involve effort, like workload or ambiguity of the role. While workload can be thought of as a challenge that motivates one to work efficiently, ambiguity is a hindrance that reduces performance. Job resources are the aspects of work that help employees to achieve their goals and to maintain their well-being at work. For example, positive social relations, development opportunities, benefits, or interesting work are motivating job characteristics that provide job satisfaction.

As has already been mentioned, job demands and resources have unique effects on employee attitudes (Bakker and Demerouti 2018). Job demands lead to chronic exhaustion and cynicism, which are the main components of burnout. In contrast, job resources are motivating and contribute positively to work engagement. Although job demands and resources have independent main effects, research has shown that job resources can buffer the impact of job demands on negative consequences like burnout (e.g. Xanthopoulou et al. 2007). In addition, both the negative consequences of job demands ("negative path") and the positive consequences of job resources ("positive path") enable the prediction of employee behavior and organizational outcomes (e.g. absenteeism, productivity, organizational citizenship behavior, client satisfaction). For example, employees who are exhausted are more likely to make mistakes, negatively impacting performance (Bakker et al. 2008), while engaged individuals perform better because they focus all their attention on their tasks (Hopstaken et al. 2015).

\section{Overview of the Current Studies}

In the presented research, we conducted two studies to explore the mediating role of the workplace self-expansion motive in the relation between working conditions (job resources and demands) and work engagement as well as organizational productive behaviors. In Study 1, we included the following job resources as predictors: the attractiveness of job tasks, compensation and benefits, relationships with others, and career development opportunities. We used self-expansion as mediator and work engagement was the dependent variable. We expected that perceiving working conditions as being rich in job resources would be positively related to work engagement, however, we also expected that this relationship would be partially mediated by workplace self-expansion (hypothesis 1). Job resources (e.g. benefits, interesting tasks, or development possibilities) are the aspects of work that help employees to achieve their goals, therefore a favourable evaluation of such aspects of work is positively related to perceiving the characteristics of work as self-expanding. This, in turn, positively correlates with work engagement. In Study 2, we extended the predictors included in the model by adding job demands and included three different dependent variables, namely: task-oriented engagement, individual-directed organizational citizenship behaviors, and organizational-directed organizational citizenship behaviors. We assumed that job resources would be related to task-oriented engagement as well as to individual- and organization-directed organizational citizenship behaviors (hypothesis 2). Furthermore, we expected that workplace self-expansion would mediate the effect of job resources on task-oriented engagement (hypothesis 3 ). Moreover, referring to job demands-resources theory, we did not expect that, after including job resources in the model, perceived job demands would be significantly related to workplace self-expansion or productive behaviors.

\section{Study 1}

\section{Method}

\section{Procedure and Participants}

A cross-sectional study was conducted on diverse organizations operating in the Polish market (1-6 employees from each organization participated in the study). The data collection was carried out from January to February 2016 via an online research platform. Access to the survey was possible only by web link received in an invitation from one of the interviewers. Participation was voluntary and anonymous. A total of 339 employees ( 205 women, i.e. $60 \%$ ) of the 420 who were initially contacted (response rate of $81 \%$ ) filled-in the complete questionnaire. Participants were between 18 and 75 years old $(M=32.74, S D=12.28)$ with an average seniority of $M=$ 12.46 years $(S D=13.39)$ and an average seniority at their current position of $M=6.54$ years $(S D=7.50)$. Participants were employees working in a variety of areas in their organizations: production (15\%), sales and customer service (35\%), organizational support (e.g. administration, HR, accounting, legal department; 21\%), and the public sector (e.g. doctor, teacher, soldier, fireman; 29\%). The sample comprised $19 \%$ managers and $81 \%$ employees in non-managerial positions. The group consisted of employees of micro (i.e. less than 10 employees; 21\%), small (i.e. from 10 to 49 employees; 28\%), medium-sized (i.e. from 50 to 249 employees; $23 \%$ ), and large (i.e. at least 250 employees; $28 \%$ ) organizations.

\section{Materials}

The measures included self-reports from questionnaires on: (a) job resources, (b) workplace self-expansion, and (c) work engagement.

Job Resources A 20-item scale was used to assess employees' perceptions of the four factors of job satisfaction: (a) positive social relations (e.g. 'I can count on help and support from my 
colleagues'); (b) development opportunities (e.g. 'The organization provides me with the opportunity to participate in attractive training and courses'); (c) remuneration and benefits (e.g. 'I am getting an attractive salary compared to wages on the market'); and (d) attractiveness of job tasks in themselves (e.g. 'The tasks I do are interesting and attractive to me'). All items were rated on a five-point Likert-like scale ( 1 = strongly disagree to $5=$ strongly agree). The scale has been previously validated in various organizations (Jurek 2017).

Workplace Self-Expansion A 14-item Workplace SelfExpansion Questionnaire developed by McIntyre et al. (2014), in its Polish adaptation by Besta and Jurek (2016), was used to assess employees' motivation to expand the boundaries of self-concept in the work environment (e.g. 'How much does your job increase your ability to accomplish new things?'). All items were rated on a five-point Likert-like scale $(1=$ strongly disagree to $5=$ strongly agree $)$.

Work Engagement Work engagement was measured using the Utrecht Work Engagement Scale (UWES), developed by Schaufeli and Bakker (2003), which measures three aspects of work engagement_-vigour (e.g. 'At my work, I feel bursting with energy'), dedication (e.g. 'My job inspires me'), and absorption (e.g. 'When I am working, I forget everything else around me')—with a seven-point scale, ranging from $0=$ never to $6=$ always. In this study, we used the Polish version of the questionnaire validated by Szabowska-Walaszczyk et al. (2011).

The results of the reliability analysis of all scales used in the current study are presented in the Results section.

\section{Analysis}

To test our hypotheses, we used structural equation modelling (SEM) with maximum likelihood estimation. SEM utilizes a confirmatory approach in order to examine the structural relations between variables using theory to shape models that attempt to explain variance in the data. We used the lavaan package (Rosseel 2012) in the $\mathrm{R}$ environment ( $\mathrm{R}$ Core Team 2017) for calculations. In the model, all variables were treated as latent variables reflecting their indicators (items or other latent variables). To assess model fit, we examined the $\chi^{2}$ statistic, the comparative fit index (CFI), and the root mean square error of approximation (RMSEA). We applied the commonly used cut-off criteria of these indices to assess model fit (i.e. CFI $>.90$ and RMSEA $<.08$ to indicate acceptable fit; e.g. Kline 2016). The mediating role of workplace self-expansion was analysed by investigating the indirect effect of job resources on work engagement. Following the recommendations of Cheung and Lau (2008), we implemented a bootstrapping procedure in which 1000 bootstrap samples were created at a 95\% confidence interval. In order to assess whether the indirect effects were significant, we used the bias-corrected percentile method. In addition, a model was tested in which we introduced age, gender, and seniority as covariates, but since the relations between the main variables remained significant, we decided not to include these demographic variables in the reported analyses.

\section{Results}

Table 1 reports the means, standard deviations, Pearson's zero-order intercorrelations, and reliabilities (on the diagonal) of the variables in Study 1. As seen in Table 1, all job resource factors were positively related to workplace self-expansion and to the three dimensions of work engagement. Furthermore, workplace self-expansion was also significantly positively correlated with vigor, dedication, and absorption.

Confirming our hypothesis, we found that job resources are related to work engagement, and that workplace selfexpansion significantly partially mediates the effect of job resources on work engagement. The results of this model are shown in Fig. 1. The tested model was an excellent fit to the data with $\chi^{2}=1361.77, d f=1214, p<0.01$, CFI $=0.99$, and RMSEA $=0.019$ (90\% C.I.: 0.012-0.024). As anticipated, the more favourable the evaluation of the job resources, the more the workplace is perceived as self-expanding - this relationship was very strong $(\beta=.84, p<.01)$. Further, workplace self-expansion had a positive, strong effect on work engagement $(\beta=.61, p<.01)$.

\section{Study 2}

\section{Method}

\section{Procedure and Participants}

A cross-sectional study was conducted on diverse organizations operating in the Polish market (1-6 employees from each organization participated in the study). The data collection was carried out from October to November 2016 via an online research platform. Access to the survey was possible only by web link received in an invitation from one of the interviewers. Participation was voluntary and anonymous. A total of 368 employees out of the 575 who were initially contacted (response rate of $64 \%$ ) filled-in the complete questionnaire. The participants were between 19 and 61 years old $(M=33.20$, $S D=11.73)$ with an average seniority of $M=12.06$ years $(S D=10.68)$ and an average seniority at their current position of $M=6.37$ years $(S D=7.67)$. Participants were employees working in a variety of areas in their 
Table 1 Means, standard deviations, and zero-order correlations among study variables (Study 1)

\begin{tabular}{|c|c|c|c|c|c|c|c|c|c|c|}
\hline Variable & M & SD & 1 & 2 & 3 & 4 & 5 & 6 & 7 & 8 \\
\hline \multicolumn{11}{|l|}{ Job resources } \\
\hline 1. Compensation and benefits & 3.19 & 0.85 & $(0.80)$ & & & & & & & \\
\hline 2. Job task & 3.56 & 0.78 & $0.47 * *$ & $(0.78)$ & & & & & & \\
\hline 3. Career development & 3.27 & 0.95 & $0.67 * *$ & $0.57 * *$ & $(0,87)$ & & & & & \\
\hline 4. Employee relationship & 4.08 & 0.71 & $0.35 * *$ & $0.29 * *$ & $0.34 * *$ & $(0.82)$ & & & & \\
\hline 5. Workplace self-expansion & 4.18 & 1.34 & $0.45 * *$ & $0.73 * *$ & $0.65 * *$ & $0.35 * *$ & $(0.96)$ & & & \\
\hline \multicolumn{11}{|l|}{ Work engagement } \\
\hline 6. Vigor & 3.66 & 1.17 & $0.40 * *$ & $0.54 * *$ & $0.45 * *$ & $0.37 * *$ & $0.63 * *$ & $(0.84)$ & & \\
\hline 7. Dedication & 3.43 & 1.46 & $0.39 * *$ & $0.69 * *$ & $0.54 * *$ & $0.31 * *$ & $0.80 * *$ & $0.80 * *$ & $(0.91)$ & \\
\hline 8. Absorption & 3.33 & 1.27 & $0.34 * *$ & $0.52 * *$ & $0.38 * *$ & $0.25 * *$ & $0.60 * *$ & $0.77 * *$ & $0.79 * *$ & $(0.87)$ \\
\hline
\end{tabular}

$N=339 . * * p<.01$, two-tailed. In diagonal brackets the alpha coefficients are given

organizations: production $(21 \%)$, sales and customer service $(39 \%)$, organizational support (e.g. administration, HR, accounting, legal department; 18\%), and the public sector (e.g. doctor, teacher, soldier, fireman; 22\%). The sample comprised $23 \%$ managers and $77 \%$ employees in non-managerial positions. The group consisted of employees of micro (i.e. less than 10 employees; 20\%), small (i.e. from 10 to 49 employees; 26\%), mediumsized (i.e. from 50 to 249 employees; 24\%), and large (i.e. at least 250 employees; $30 \%$ ) organizations.

\section{Materials}

The measures included self-reports from questionnaires on: (a) job resources, (b) job demands, (c) workplace self-expansion, and (d) productive behaviors. Job resources and workplace self-expansion were measured using the same tools as in Study 1.

Job Demands A 34-item Organizational Role Stressors Index developed by Jurek (2016) was used to assess employees'

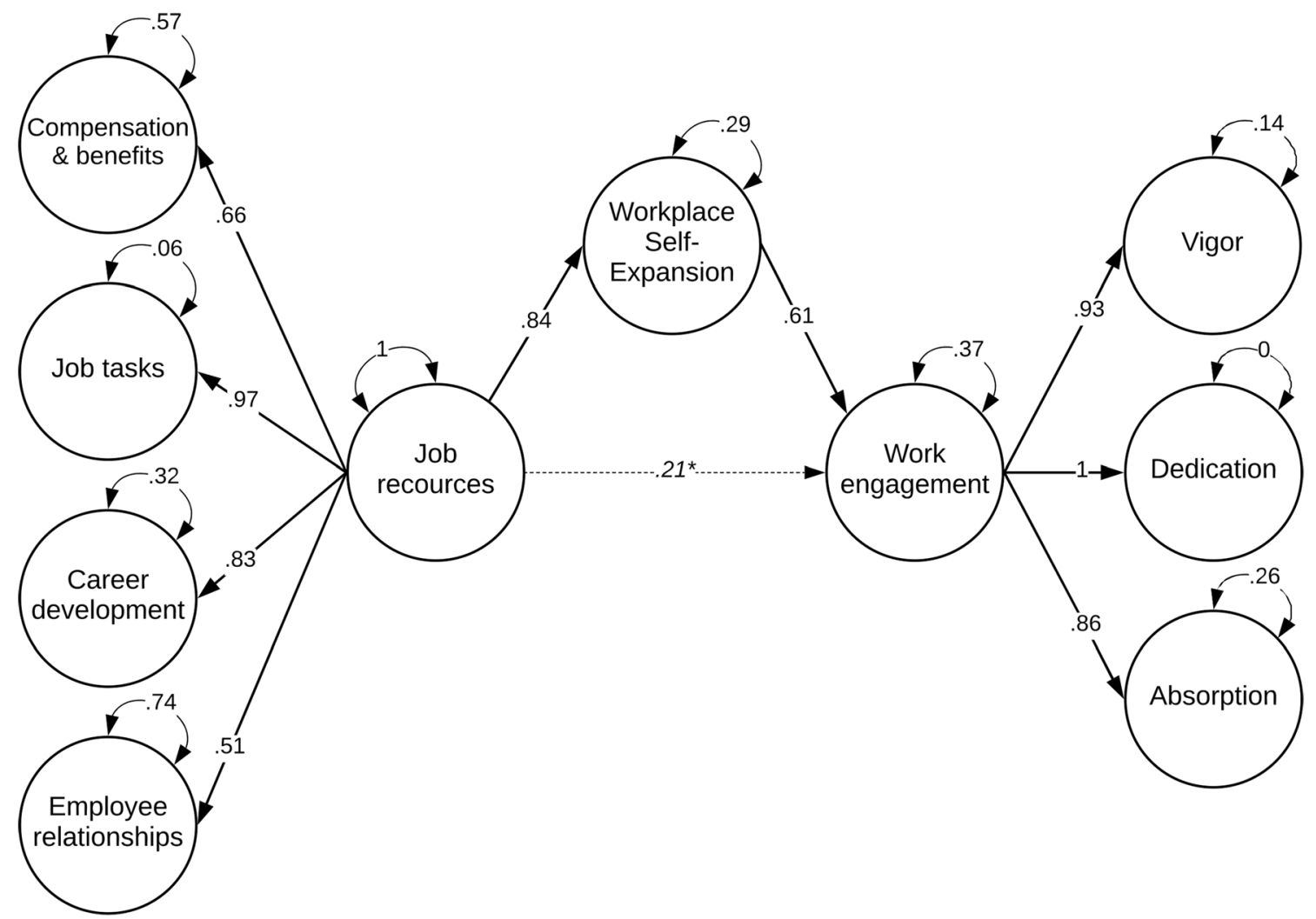

Fig. 1 Results of structural equation modelling - internal model of latent variables (Study 1, $N=339$. Standard estimates are reported. All paths marked with a solid line are significant at $p<.01$; the path marked with a dotted line is statistically significant at $p<.05$ ) 
perceptions of the four categories of barriers to efficient performance: (a) role conflict (e.g. 'Superiors having contradictory requirements'); (b) role ambiguity (e.g. 'Lack of clarity on how to perform my work'); (c) role overload (e.g. 'Too many tasks in a given time'); and (d) role undervaluation (e.g. 'Lack of appreciation for the work done'). The participants assessed on a five-point scale how often they experience each of 34 situations in the workplace $(1=$ never to $5=$ always - every day $)$.

Productive Behaviors Three four-item scales were designed for this study to measure the productive behaviors of employees. The first scale consists of items from Saks (2006) describing behaviors indicating task-oriented engagement (e.g. 'Sometimes I am so into my job that I lose track of time'); the second and the third scales consist of items from Lee and Allen (2002) describing, respectively, behaviors indicating organizational citizenship behaviors directed towards individuals (e.g. 'Willingly give your time to help others who have work-related problems') and behaviors indicating organizational citizenship behaviors directed towards the organization (e.g. 'Take action to protect the organization from potential problems'). All items were rated on a five-point Likert-like scale $(1=$ strongly disagree to $5=$ strongly agree $)$.

The results of the reliability analysis of all scales used in the current study are presented in the results section.

\section{Analysis}

To test our hypotheses, we repeated the analysis strategy from Study 1 . We performed structural equation modelling with maximum likelihood estimation. In the model, all variables were treated as latent variables reflected by their indicators (items or other latent variables). To assess model fit, we applied the same cut-off criteria as in Study 1 for selected fit indices (i.e. CFI > .90 and RMSEA < .08). The mediating role of workplace self-expansion was analysed by investigating the indirect effect of job resources and demands on three types of productive behaviors. We also implemented a bootstrapping procedure with 1000 bootstrap samples at a $95 \%$ confidence interval. In order to assess whether the indirect effects were significant, we used the bias-corrected percentile method. As in the previous study, a model was tested in which we introduced age, gender, and seniority as covariates, but since the relations between the main variables remained significant, we decided not to include these demographic variables in the reported analyses.

\section{Results}

Table 2 reports the means, standard deviations, Pearson's zero-order correlations, and reliabilities (on the diagonal) of the variables in Study 2. As seen in Table 2, all job resource

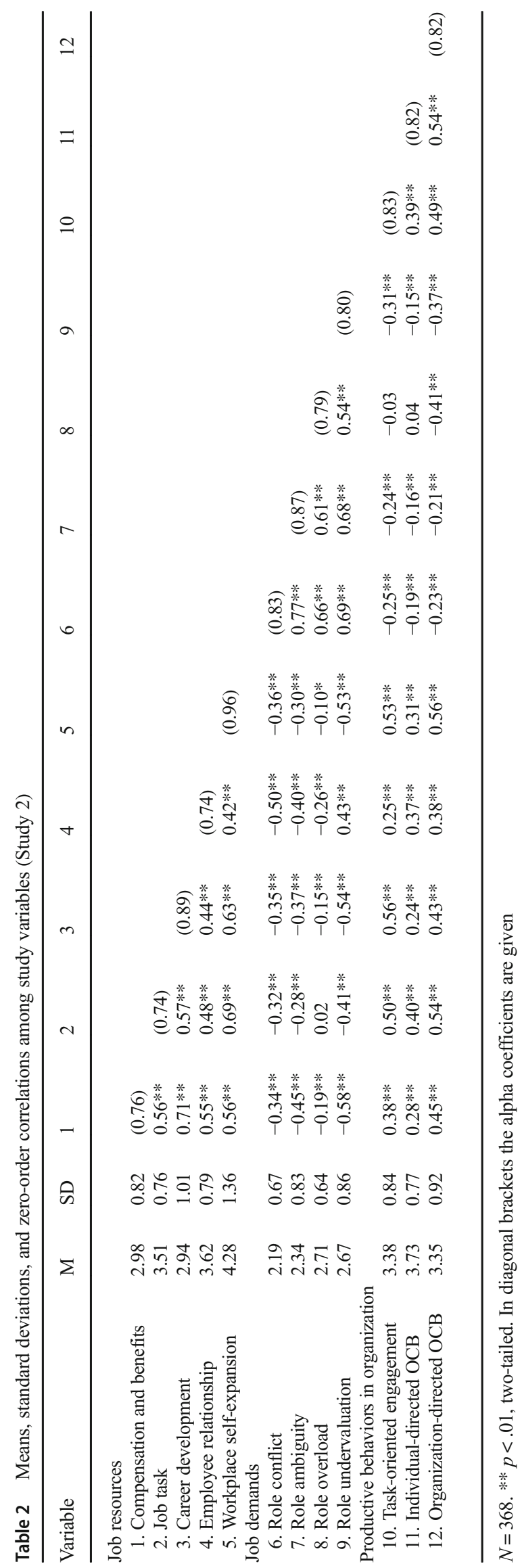


factors were positively related to workplace self-expansion and to the three forms of organizational productive behaviors. Furthermore, workplace self-expansion was also significantly positively correlated with task-oriented engagement, as well with individual- and organization-directed organizational citizenship behaviors. The opposite relationship was observed for job demands variables (except for role overload, which significantly negatively correlated only with organizationaldirected organizational citizenship behaviors).

Confirming our hypothesis, we found that job resources (but not job demands) are related to task-oriented engagement as well as to individual- and organization-directed organizational citizenship behaviors. Furthermore, workplace self-expansion fully mediates the effect of job resources on task-oriented engagement, but not on organizational citizenship behaviors. The results of this model are shown in Fig. 2. The tested model was an excellent fit to the data with $\chi^{2}=7188.54, d f=3057, p<0.01, \mathrm{CFI}=0.95$, and RMSEA $=0.061$ (90\% C.I.: 0.059-0.063). As anticipated, evaluation of job resources is strongly positively related with perceiving the workplace as selfexpanding - this relationship was very strong $(\beta=.84$, $p<.01)$. Moreover, workplace self-expansion had a positive effect on task-oriented engagement $(\beta=.44, p<.01)$ and only a moderate positive effect on organizationdirected organizational citizenship behaviors $(\beta=.28$, $p<.05)$. However, there was no significant relationship between workplace self-expansion and individualdirected organizational citizenship behaviors, taking into account job resources in the model. Individual- as well as organization-directed organizational citizenship behaviors were directly positively related with perceived job resources (respectively: $\beta=.53$ and $\beta=.49, p<.01$ ). We also found that job demands assessed by employees do not affect their workplace self-expansion if the role of job resources is included.

\section{General Discussion}

In these two studies we investigated the mediating role of workplace self-expansion in the relationship between job resources and job demands with work engagement and productive behaviors. We used a self-expansion model perspective and job demands-resources theory to frame the research questions. Current research on the relationships between employees' attitudes and behaviors with job demands/resources indicates that greater specificity is needed to develop a more informed understanding of these relationships; in this context, the present studies took a valuable step forward.

The idea that job demands lead to negative consequences while job resources are motivating and contribute positively to work engagement is not a new one (Bakker and Demerouti 2018). However, the present studies expand these findings by searching for and testing potential mediators that elucidate how job resources are related to the expansion of self-concept. In particular, simultaneously examining job demands and resources as well as workplace self-expansion better articulates the relationships between job conditions, work engagement, and productive behaviors. Our findings suggest that positive work conditions (job resources), as perceived by employees, are related to work and task-oriented engagement and that this relationship is mediated by employees' workplace self-expansion. It appears that individuals who see in their workplace interesting tasks, development opportunities, good relations with colleagues, and satisfying rewards identify their workplace with an environment that contributes to the self-expansion process, which is related to self-growth, acquiring new perspectives, and mental resources. This, in turn, affects positive attitudes towards work and behavioural taskoriented engagement. At the same time, our findings prove that high job demands (e.g. role ambiguity, overload) do not weaken employees' self-expansion if we take into account the effect of job resources. This effect is consistent with research on romantic self-expansion, in which positive aspects of relationships are linked to selfexpansion (Aron and Aron 1996). Similarly, analyses of the inclusion of important groups into the self highlight that when the external environment is not supportive (i.e. because of uncertainty), self-expansion is no longer a salient motive. Thus, in a secure and safe social context, people can self-expand to a greater or lesser extent, depending on the people around them and the activities they are involved in. In uncertain and unsafe contexts, self-expansion is a less relevant need, as people are motivated to regain control and certainty (Wright et al. 2002). Our results are also in line with the basic assumptions of job demands-resources theory (Bakker and Demerouti 2018). They also elaborate on the workplace self-expansion model (McIntyre et al. 2014) by pointing to the important role of satisfaction factors in satisfying the need for self-expansion.

We also found that workplace self-expansion does not mediate the relationship between perceived job resources and organizational citizenship behaviors. That is, a favourable work environment directly affects additional (other than task-oriented) activities which are of benefit to organizations and collaborators. In this case-in line with the unified theory of social relations (Fiske 1992) and according to the rule of proportionality-working conditions perceived as beneficial are conducive to engaging in extra-role activities. Self-expansion typically occurs as a result of completing more tasks and thus acquiring 


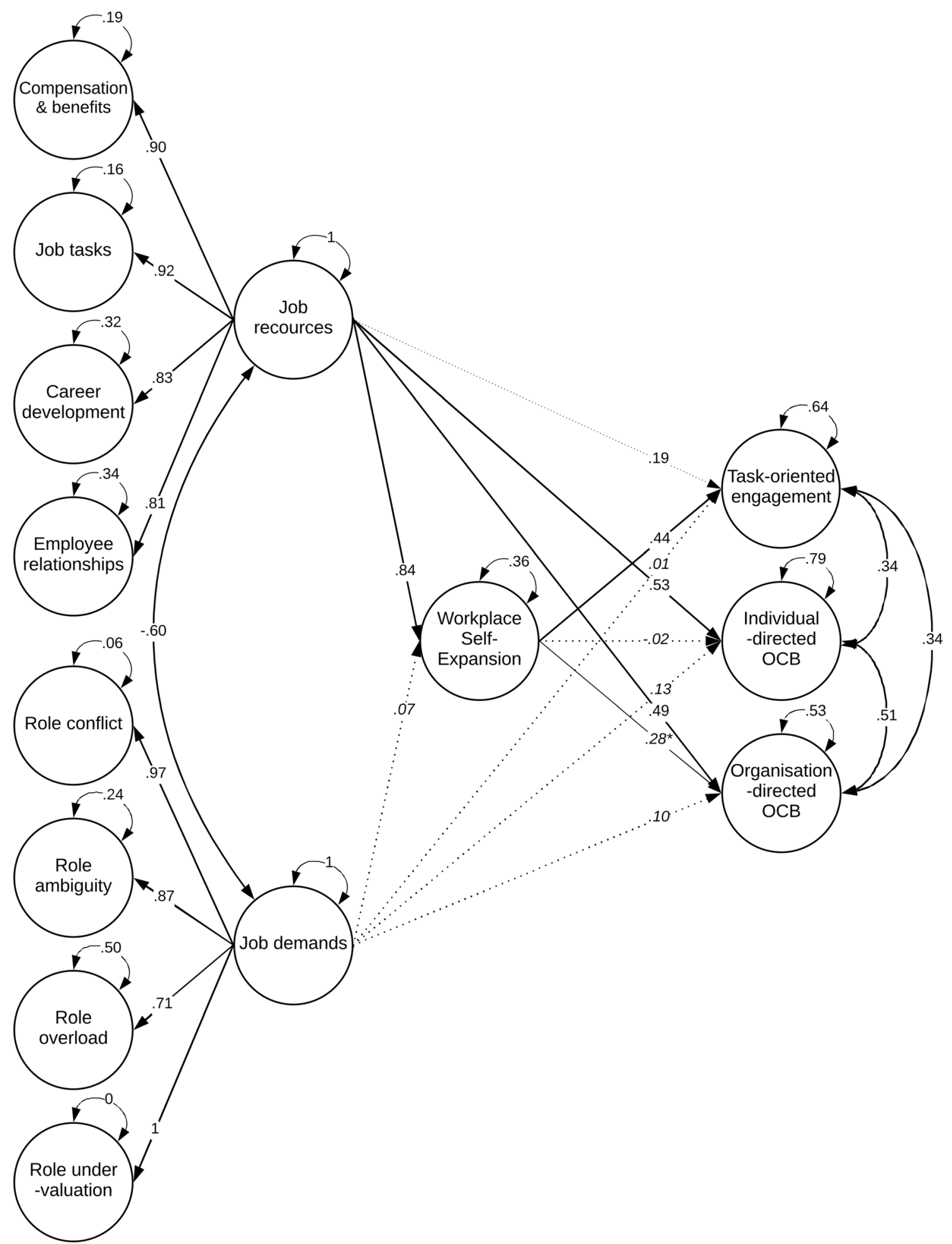

Fig. 2 Results of structural equation modelling - internal model of latent variables (Study 2, $N=368$. Standard estimates are reported. All paths marked with a solid line are significant at $p<.01$; the path marked with a dotted line is statistically insignificant at $p<.05$ )

new resources that expand psychological capital (see McIntyre et al. 2014). Experience of this kind positively relates to willingness to perform tasks which employees perceive as challenging and developmental. This phenomenon does not necessarily occur in the case of organizational citizenship behaviors, which go beyond one's occupational role and, being beneficial primarily for the organization, are directly related to the perceived benefits of being a part of the organization (according to the rules of social exchange). 


\section{Limitations and Directions for Future Research}

Our results should be considered in the context of several potential limitations. First, the data were cross-sectional, which means that our findings provided insight only into correlations between perceived work conditions, workplace self-expansion, and the dependent variables. Therefore, future longitudinal research is required to identify causality. Moreover, the predictors (job resources and job demands), the mediator (workplace self-expansion), and outcomes (work engagement and productive behaviors) were measured using self-report scales and collected at the same time, which may suggest the issue of common-method variance or participants' global feelings about their job being a factor underlying all measured variables. It would be advisable to confirm our results in a study in which employees' attitudes and behaviors are assessed by their superiors. Finally, our focus on work engagement and productive behaviors may limit the scope of our findings. It would be beneficial to extend the research with objective measures of work performance and outcomes. It is possible that the mediating role of workplace self-expansion on the relationship between perceived job resources and work and task-oriented engagement might differ based on employees' outcomes.

\section{Implications for Practice}

Our findings suggest some useful implications for HR professionals and managers. The key conclusion of our studies is the need to consider the process of shaping self-concept when designing efficient work conditions, which, to date, has been ignored in favour of focussing on improving the work environment by removing stressors. Of course, such changes are good and can bring positive outcomes; however, our findings show that removing stressors may not be enough to build employee engagement. Our findings highlight the role of employees' self-expansion in determining their work attitudes. As has been shown, work and task-oriented engagement is related to employees experiencing working conditions that shape their self-expansion, i.e. high levels of job resources, rather than low job demands. Therefore, to create an engaging work environment, HR professionals and managers should consider motivational factors first. Our findings, considered in the context of previous research, show that limiting organizational stressors in the work environment can protect employees against burnout, but will not guarantee their engagement. We conclude that a lack of job demands does not facilitate self-growth and self-expansion, whereas high job resources do.

\section{Compliance with Ethical Standards}

Conflict of Interest On behalf of all authors, the corresponding author states that there is no conflict of interest.

Open Access This article is distributed under the terms of the Creative Commons Attribution 4.0 International License (http:// creativecommons.org/licenses/by/4.0/), which permits unrestricted use, distribution, and reproduction in any medium, provided you give appropriate credit to the original author(s) and the source, provide a link to the Creative Commons license, and indicate if changes were made.

\section{References}

Aron, E. N., \& Aron, A. (1996). Love and expansion of the self: The state of the model. Personal Relationships, 3, 45-58. https://doi.org/10. 1111/j.1475-6811.1996.tb00103.x.

Aron, A., Paris, M., \& Aron, E. N. (1995). Falling in love: Prospective studies of self-concept change. Journal of Personality and Social Psychology, 69(6), 1102-1112. https://doi.org/10.1037/0022-3514. 69.6.1102.

Bakker, A. B., \& Demerouti, E. (2017). Job demands-resources theory: Taking stock and looking forward. Journal of Occupational Health Psychology, 22, 273-285.

Bakker, A. B., \& Demerouti, E. (2018). Multiple levels in job demandsresources theory: Implications for employee well-being and performance. In E. Diener, S. Oishi, \& L. Tay (Eds.), Handbook of wellbeing. Salt Lake City: DEF Publishers.

Bakker, A. B., Van Emmerik, H., \& Van Riet, P. (2008). How job demands, resources, and burnout predict objective performance: A constructive replication. Anxiety, Stress, and Coping, 21, 309-324.

Besta, T., \& Jurek, P. (2016). Zastosowanie skali poczucia rozszerzenia Ja w miejscu pracy w warunkach polskich [The Workplace Self-expansion Questionnaire in a Polish context]. Psychologia Ekonomiczna, 10, 41-58. https://doi.org/10.15678/ PJOEP.2016.10.04.

Besta, T., Mattingly, B., \& Błażek, M. (2016). When membership gives strength to act: Inclusion of the group into the self and feeling of personal agency. The Journal of Social Psychology, 156(1), 56-73. https://doi.org/10.1080/00224545.2015.1053838.

Besta, T., Jaśkiewicz, M., Kosakowska-Berezecka, N., Lawendowski, R., \& Zawadzka, A. M. (2018). What do I gain from joining crowds? Does self-expansion help to explain the relationship between identity fusion, group efficacy and collective action. European Journal of Social Psychology, 48, O152-O167. https://doi.org/10.1002/ejsp.2332.

Bono, J. E., \& Judge, T. A. (2003). Core self-evaluations: A review of the trait and its role in job satisfaction and job performance. European Journal of Personality, 17, 5-18. https://doi.org/10.1002/per.481.

Chan, X. W., Kalliath, T., Brough, P., Siu, O.-L., O’Driscoll, M. P., \& Timms, C. (2016). Work-family enrichment and satisfaction: The mediating role of self-efficacy and work-life balance. The International Journal of Human Resource Management, 27(15), 1755-1776. https://doi.org/10.1080/09585192.2015.1075574.

Cheung, G. W., \& Lau, R. S. (2008). Testing Mediation and Suppression Effects of Latent Variables: Bootstrapping With Structural Equation Models. Organizational Research Methods, 11(2), 296-325. https:// doi.org/10.1177/1094428107300343

Fiske, A. P. (1992). The four elementary forms of sociality: Framework for a unified theory of social relations. Psychological Review, 99(4), 689-723. 
Hopstaken, J. F., Van der Linden, D., Bakker, A. B., \& Kompier, M. A. J. (2015). A multifaceted investigation of the link between mental fatigue and task disengagement. Psychophysiology, 52, 305-315.

Hytti, U., Kautonen, T., \& Akola, E. (2013). Determinants of job satisfaction for salaried and self-employed professionals in Finland. The International Journal of Human Resource Management, 24(10), 2034-2053. https://doi.org/10.1080/09585192.2012.723023.

Judge, T. A., \& Bono, J. E. (2001). Relationship of core self-evaluations traits-Self-esteem, generalized self-efficacy, locus of control, and emotional stability - With job satisfaction and job performance: A meta-analysis. Journal of Applied Psychology, 86, 80-92. https:// doi.org/10.1037//0021-9010.86.1.80.

Jurek, P. (2016). Organizational role stressor index: A new tool in the study of barriers to building employee engagement. Zarzadzanie Zasobami Ludzkimi [Human Resources Management], 3-4(110 111), 173-192.

Jurek, P. (2017). The psychometric properties of the SAT-20 scale: A new tool to measure job satisfaction. Zarzadzanie Zasobami Ludzkimi [Human Resource Management], 2(115), 104-126.

Kline, R. B. (2016). Principles and practice of structural equation modelling (4th ed.). New York: The Guilford Press.

Knippenberg, D. V., \& Sleebos, E. (2006). Organizational identification versus organizational commitment: Self-definition, social exchange, and job attitudes. Journal of Organizational Behavior, 27, 571-584. https://doi.org/10.1002/job.359.

Lee, J. (2003). An analysis of the antecedents of organization-based selfesteem in two Korean banks. The International Journal of Human Resource Management, 14(6), 1046-1066. https://doi.org/10.1080/ 0958519032000106207.

Lee, K., \& Allen, N. J. (2002). Organizational citizenship behavior and workplace deviance: The role of affect and cognitions. Journal of Applied Psychology, 87, 131-142. https://doi.org/10.1037/00219010.87.1.131

Lin, X. S., Qian, J., Li, M., \& Chen, Z. X. (2016). How does growth need strength influence employee outcomes? The roles of hope, leadership, and cultural value. The International Journal of Human Resource Management, online first, 1-28. https://doi.org/10.1080/ 09585192.2016.1255901.

Little, T. D., Snyder, C. R., \& Wehmeyer, M. (2006). The agentic self: On the nature and origins of personal agency across the life span. In D. K. Mroczek \& T. D. Little (Eds.), Handbook of personality development (pp. 61-79). Mahwah: LEA.

Mattingly, B. A., \& Lewandowski, G. W., Jr. (2013). The power of one: Benefits of individual self-expansion. The Journal of Positive Psychology, 8(1), 12-22. https://doi.org/10.1080/ 17439760.2012 .746999$.

Mattingly, B. A., \& Lewandowski, G. W., Jr. (2014). Expanding the self brick by brick: Nonrelational self-expansion and self-concept size. Social Psychological and Personality Science, 5(4), 484-490. https://doi.org/10.1177/1948550613503886.
Mattingly, B. A., Mcintyre, K. P., \& Lewandowski, G. W., Jr. (2012). Approach motivation and the expansion of self in close relationships. Personal Relationships, 19, 113-127. https://doi.org/10. 1111/j.1475-6811.2010.01343.x.

McIntyre, K. P., Mattingly, B. A., Lewandowski, G. W., Jr., \& Simpson, A. (2014). Workplace self-expansion: Implications for job satisfaction, commitment, self-concept clarity, and self-esteem among the employed and unemployed. Basic and Applied Social Psychology, 36(1), 59-69. https://doi.org/10. 1080/01973533.2013.856788.

Meyer, J. P., Becker, T. E., \& Dick, R. V. (2006). Social identities and commitments at work: Toward an integrative model. Journal of Organizational Behavior, 27(5), 665-683. https:// doi.org/10.1002/job.383.

R Core Team (2017). R: A language and environment for statistical computing. R Foundation for Statistical Computing. Received from http://www.R-project.org. Accessed 21 Dec 2017

Rosseel, Y. (2012). Lavaan: An R package for structural equation modelling. Journal of Statistical Software, 48(2), 1-36. https://doi.org/10. 18637/jss.v048.i02.

Saks, A. M. (2006). Antecedents and consequences of employee engagement. Journal of Managerial Psychology, 21(7), 600-619. https:// doi.org/10.1108/02683940610690169.

Schaufeli, W. B., \& Bakker, A. B. (2003). Utrecht work engagement scale: Preliminary manual. Occupational Health Psychology Unit, Utrecht University, Utrecht. Received from https://www. wilmarschaufeli.nl. Accessed 4 Jan 2016

Szabowska-Walaszczyk, A., Zawadzka, A. M., \& Wojtaś, M. (2011). Zaangażowanie w pracę i jego korelaty: Adaptacja skali UWES autorstwa Schaufeliego i Bakkera [work engagement and its correlations: Adaptation of the Schaufeli and Bakker UWES scale]. Psychologia Jakosİci Życia, 10(1), 57-74.

Wright, S. C., Aron, A., \& Tropp, L. R. (2002). Including others (and groups) in the self: Self-expansion and intergroup relations. In J. P. Forgas \& K. D. Williams (Eds.), The social self: Cognitive, interpersonal and intergroup perspectives (pp. 343-368). New York: Psychology Press.

Xanthopoulou, D., Bakker, A. B., Dollard, M. F., Demerouti, E., Schaufeli, W. B., Taris, T. W., \& Schreurs, P. J. G. (2007). When do job demands particularly predict burnout? The moderating role of job resources. Journal of Managerial Psychology, 22, 766-786. https://doi.org/10.1108/02683940710837714.

Xu, X., Floyd, A. H. L., Westmaas, J. L., \& Aron, A. (2010). Selfexpansion and smoking abstinence. Addictive Behaviors, 35(4), 295-301. https://doi.org/10.1016/j.addbeh.2009.10.01.

Publisher's note Springer Nature remains neutral with regard to jurisdictional claims in published maps and institutional affiliations. 